\title{
Team Approach Or Individual Approach: A Statistical Analysis Of The Impact Of Socioeconomic Heterogeneity On Students' Preference In Writing Term Papers In Management Courses
}

\author{
Tyler T. Yu, (E-mail: tyu@ggc.usg.edu), Georgia Gwinnet College \\ Victoria Johnson, (E-mail: VJohnson@ggc.usg.edu), Georgia Gwinnet College \\ Miranda M. Zhang, (E-mail: zhang_mm@ mercer.edu), Mercer University \\ Lloyd Southern, (E-mail: Southern_1@mercer.edu), Mercer University
}

\begin{abstract}
The purpose of this paper is to examine students' preference in writing term papers in management courses. Specifically, students' attitudes and preferences toward the choices, i.e., whether it is written as an individual effort, or as a team effort, are examined. These choices (individual approach, team approach, freedom of choice and indifferent) are then tested against a set of socioeconomic factors to see if there are significant relationships among the variables. The paper reports the empirical findings of the study.
\end{abstract}

\section{INTRODUCTION}

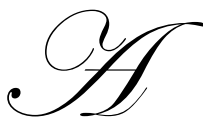

lthough team-building and teamwork are concepts, which had been previously utilized and institutionalized by successful companies such as Volvo, Toyota and General Foods, the mid-1970's witnessed a heightened interest in the use of teamwork and team-building in organizational processes and structures. Subsequently, teamwork and team-based structures gained significant popularity and acceptance in the business world during the 1980s and 1990s, (Applebaum and Blatt, 1994). Generally, empirical studies contend that team approaches typically do better than individual approaches for tasks and circumstances requiring multiple skills, judgment and experience (Katzenbach and Smith, 1993).

As team-structures and team-based work forces gained popularity within the corporate environment, business schools started their own crusade preaching the importance of teamwork and emphasizing team-based pedagogical approaches in business education (Bolton, 1999). The goal of such pedagogical approaches is to better prepare the students for the real business world. In pursuing this goal, it is generally postulated that students also prefer such an academic approach or they are insouciant about the alternatives. This is especially the case with the increasing number of "non-traditional" students, who may have to assume different roles in life-parents at home, employees in organizations, and students in the business education programs. All these roles consume and compete for their time.

In a majority of business degree programs, it is a common pedagogical approach to require students to write term papers for partial fulfillments of course requirements. When doing so, students are either required to write their papers individually, or as a team or group. Sometimes, professors will permit freedom of choice. Although "group" and "team" are sometimes used interchangeably, there are differences between the two. This paper uses the following definitions. A work group is defined as two or more individuals getting together to achieve particular objectives, while a work team is designed to create positive synergy (Robbins, 2000). A team, not a group, should be used as a substitute for individual effort in term paper writing because $t$ some level of synergy can be created with such a team 
approach effort. Of course, in reality, that is not always the case. A work group's synergy can be positive, neutral or even negative (Robbins, 2000).

\section{PURPOSE AND OBJECTIVES}

The purpose of this paper is to examine students' preferences for different methods of writing term papers. The primary question is which approach do students prefer: team or individual? A concomitant question, equally important, is what factors affect their preferences and choices, and how significant are these effects?

For this study, a survey was designed to examine the relationships between the common choices (individual effort, team effort, or indifferent) and a set of socioeconomic factors (age, gender, race/ethnicity, marital status, work experience, employment status, income level and educational level). Then, a survey result will be reported on the basis of descriptive and probabilistic statistical analyses. A series of hypothesis tests using $\chi 2$-statistic was conducted to determine the statistical significance of the impact of these factors on the choices of writing term papers.

\section{REVIEW OF LITERATURE}

Business research literature has offered ideas, suggestions and study results regarding the use of team or group projects in business education. In one aspect, researchers have conducted studies to examine the evolution of pedagogical approaches designed to help students learn team-building skills in business programs. In a case study conducted with MBA students as a sample, Tonn and Milledge (2002) described the obstacles they had to overcome to achieve their goals in teaching team-building skills in a new capstone course for an MBA program serving largely part-time working professionals at the University of Massachusetts, Boston. The critical components to teambuilding, according to the authors, are 1) managing students' expectations, 2) addressing challenges and opportunities posed by diversity, and 3) supporting and rewarding team development. Another study, also treating MBA students as its sample, was conducted in the College of Business Administration at the University of Tulsa. The purpose of the study was to identify measures that could be used to harness the vexing problems of failing teams or teamwork, social loafing, slacking, and lack of commitment. A new method called "Team Frame" was designed to with the dual purposes of introducing students to the concept of framing, while providing a teambuilding experience. In the study the team frame exercise contributed to the development of more effective teams (Bowen, 1998).

Ettington and Camp (2002) proposed several principles that can be and should be used to facilitate the transfer of skills between group projects and work teams. For example, the authors suggest that an assessment of students' skills using development needs be conducted before attempting to develop their skills using group projects. The study contends that instructors must be mindful when using group projects of how their actions affect final objectives. If the objective is for students to develop transferable skills, then professors should assess the probability of success by applying the proposed principles of transfer. The authors, using their experience, made six recommendations related to the transfer principles.

Also with regard to research methodology, Chatman and Flynn (2001) examined the influence of demographic heterogeneity on the emergence and consequences of cooperative norms in work teams. In designing their study, the authors utilized 119 students enrolled in a two-year full-time MBA program at a major American university as their sample. The students were first divided into groups doing experimental consulting work. Then, a survey was conducted to collect data regarding team experience.

A group of studies was conducted to examine different aspects of team/group approaches in business practice. Bingham and Quigley (1989) presented a new product implementation process, which was designed to reduce the risk inherent in new product design and development. A team approach is one that combines decision makers from key areas within the firm. A continuous team that assumes responsibility for implementing the new product development process characterizes the new team approach. A case study was conducted to look at the role of social style as a technique that could be used to facilitate teambuilding in small business firms (Darling, 1990). Moreover, according to the study, social style, which has two critical dimensions of interpersonal behaviorassertiveness, and responsiveness-is the key to organizational effectiveness and goal achievement in the small 
business setting (Banner et al, 1992). Organizational structure changes, including self-managing work teams (SMWT), have created challenges to the traditional role of human resource functions. The new role of supervisors will be more one of "facilitators and coach rather than one of "rule enforcer/nay sayer." Thus, the human resource function can become a true support unit to the SMWTs.

\section{ANALYSIS}

The characteristics of the sample used in this study resemble the ones used by previous studies. The student sample is composed of students who attend a business school in a major metropolitan area in the Southeast. The students are non-traditional, adult learners. Nearly $80 \%$ of these students are enrolled in MBA and/or MS in Healthcare degrees on a part-time basis and are employed full-time in the metropolitan area. The remaining student body, mostly international students, do not work and pursue degrees full-time. Therefore, courses are scheduled only in the evenings and on Saturdays. The students are diversified in terms of gender (about 50\% women and 50\% men), educational background (e.g., arts and science, engineering, business, and education), and national origins (about $20 \%$ are international students from various countries in Europe, South America and Asia).

The following constitutes the analysis of 248 observations in a survey concerning the students' preference toward the approaches to writing management term papers. In the survey, eight variables were taken into consideration to examine students' attitudes toward writing term papers: age, gender, race or ethnicity, martial status, employment status, income level, work experience, and educational background. The following tables demonstrate the joint and marginal probability analysis of the variables selected for this study.

Table 1: Age

\begin{tabular}{|c|c|c|c|c|c|}
\hline & $\mathbf{2 2 - 3 2}$ & $\mathbf{3 3 - 4 2}$ & $\mathbf{4 3 - 5 2}$ & Over 52 & Total \\
\hline Individual & 0.2571 & 0.0857 & 0.0448 & 0.0040 & 0.3877 \\
\hline Team & 0.2734 & 0.0734 & 0.0244 & 0.0000 & 0.3755 \\
\hline Choices & 0.1306 & 0.0204 & 0.0163 & 0.0040 & 0.1714 \\
\hline Indifferent & 0.0448 & 0.0163 & 0.0000 & 0.0040 & 0.0653 \\
\hline Total & 0.7061 & 0.1959 & 0.0885 & 0.0122 & 1.0000 \\
\hline
\end{tabular}

The marginal and joint probabilities from Tables 1, 2, and 3 show the joint and marginal probabilities derived for age, gender, and race/ethnicity. For instance, the probability for a person to be between 22 and 32 and prefer team approach is 25.71 percent. Given that the person is between 33 and 42, the probability for that person to prefer individual approach to term paper writing is $43.74 \%(0.0857 / 0.1959)$. The probability for a person to prefer team approach and to be female is 16.32 percent. The probability for a person to be male and to prefer individual approach is 17.14 percent. Given that the person is a male, the probability for that person to be indifferent to the choices is $9.07 \%(0.0489 / 0.5387)$. Given that the person is a female, the probability for that person to prefer freedom of choice 14.15 percent $(0.0653 / 0.4612)$. Using the marginal and joint probabilities from tables 5 and 6 , the following conclusions can be drawn. The probability for a person to be white and to prefer individual approach is 18.36 percent. The probability for a person to be black and to prefer individual approach is 17.95 percent.

Table 2: Gender

\begin{tabular}{|c|c|c|c|}
\hline & Male & Female & Total \\
\hline Individual & 0.1714 & 0.2163 & 0.3877 \\
\hline Team & 0.2122 & 0.1632 & 0.3755 \\
\hline Choices & 0.1061 & 0.0653 & 0.1714 \\
\hline Indifferent & 0.0489 & 0.0163 & 0.0653 \\
\hline Total & 0.5387 & 0.4612 & 1.0000 \\
\hline
\end{tabular}


Table 3: Race/Ethnicity

\begin{tabular}{|c|c|c|c|c|c|}
\hline & Black & White & Hispanic & Asian & Total \\
\hline Individual & 0.1795 & 0.1836 & 0.0204 & 0.0163 & 0.3877 \\
\hline Team & 0.1877 & 0.1714 & 0.0081 & 0.0571 & 0.3755 \\
\hline Choices & 0.0693 & 0.0816 & 0.0000 & 0.0204 & 0.1714 \\
\hline Indifferent & 0.0244 & 0.0204 & 0.0040 & 0.0040 & 0.0530 \\
\hline Total & 0.4122 & 0.4571 & 0.0326 & 0.0979 & 1.0000 \\
\hline
\end{tabular}

Table 4: Employment Status

\begin{tabular}{|c|c|c|c|c|}
\hline & Full time & Part time & Not working & Total \\
\hline Individual & 0.3061 & 0.0285 & 0.0530 & 0.3877 \\
\hline Team & 0.2326 & 0.0408 & 0.0938 & 0.3755 \\
\hline Choices & 0.1428 & 0.0081 & 0.0285 & 0.1795 \\
\hline Indifferent & 0.0571 & 0.0000 & 0.0081 & 0.0653 \\
\hline Total & 0.7387 & 0.0775 & 0.1836 & 1.0000 \\
\hline
\end{tabular}

Using the marginal and joint probabilities displayed in Tables 4, 5 and 6, some relationships between factors of employment status, income levels and marital status and students' attitudes toward approaches of writing term papers in management courses can be shown. For example, the probabilities for a person to be employed full-time or not employed and to prefer team approach are $23.26 \%$ and $9.38 \%$, respectively. The probabilities of full-time employed people preferring individual approach or freedom of choice are $30.61 \%$ and $14.28 \%$, respectively. In terms of income, the probability for a person to have an income between $35 \mathrm{k}$ to $75 \mathrm{k}$ and to prefer team approach is 20.00 percent. The probability for a person to have an income $35 \mathrm{k}$ or less and to consider individual approach as the best choice is 11.02 percent. Given that a person has an income between $\$ 35 \mathrm{~K}$ and $\$ 75 \mathrm{k}$, the probabilities that such a person prefers an individual approach or a team approach are 38.25\% (0.2326/0.6081), or 32.88\% (0.2000/0.6081), respectively. In Table 6, various marginal and joint probabilities showing the relationship between marital status and preference toward term paper writing approaches are estimated and demonstrated. Slightly more singles prefer team approach than married people, $18.75 \%$ versus 18.36 percent, respectively.

Table 5: Income

\begin{tabular}{|c|c|c|c|c|}
\hline & 35k or less & 35k -75k & Over 75k & Total \\
\hline Individual & 0.1102 & 0.2326 & 0.0448 & 0.3877 \\
\hline Team & 0.1102 & 0.2000 & 0.0514 & 0.3673 \\
\hline Choices & 0.0408 & 0.1265 & 0.0122 & 0.1795 \\
\hline Indifferent & 0.0040 & 0.0489 & 0.0122 & 0.0653 \\
\hline Total & 0.2853 & 0.6081 & 0.1265 & 1.0000 \\
\hline
\end{tabular}

Table 6: Marital Status

\begin{tabular}{|c|c|c|c|}
\hline & Married & Single & Total \\
\hline Individual & 0.1877 & 0.2122 & 0.4000 \\
\hline Team & 0.1836 & 0.1918 & 0.3755 \\
\hline Choices & 0.0816 & 0.0897 & 0.1714 \\
\hline Indifferent & 0.0408 & 0.0122 & 0.0530 \\
\hline Total & 0.4938 & 0.5061 & 1.0000 \\
\hline
\end{tabular}


Table 7: Experience

\begin{tabular}{|c|c|c|c|c|}
\hline & 5 yrs or less & $\mathbf{5 - 1 0 ~ Y r s}$ & Over 10 Yrs & Total \\
\hline Individual & 0.0816 & 0.1673 & 0.1387 & 0.3877 \\
\hline Team & 0.1959 & 0.1142 & 0.0612 & 0.3714 \\
\hline Choices & 0.0734 & 0.0612 & 0.0448 & 0.1795 \\
\hline Indifferent & 0.0244 & 0.0285 & 0.0081 & 0.0612 \\
\hline Total & 0.3755 & 0.3714 & 0.2530 & 1.0000 \\
\hline
\end{tabular}

Tables 7 and 8 show the impact of work experience and educational background on students' attitudes toward term paper writing approaches. For instance, the probability for a person with 5-10 years experience and to prefer team approach is 11.42 percent. The probability for a person with over 10 years of experience and to consider individual approach as the best way to write management papers is 13.87 percent Given that a person has less than five years of experience, the probability for that person to be indifferent to the choices is 6.50 percent $(0.0244 / 0.3755)$. As shown in Table 8, the probability for a person to have a business education and to consider the team approach as the best way to write management papers is 26.53 percent. The probability for a person to have an arts and science degree and to consider team approach as the best way of writing management term paper is 7.75 percent. Given that a person has an undergraduate education in business, the probability for that person to consider an individual approach as the best way is $36.02 \%(0.2367 / 0.6571)$. Given that a person has an arts and science background, the probability to consider an individual approach as the best method is $47.15 \%(0.1020 / 0.2163)$. Given that a person has an engineering background, the probability for that person to consider the individual approach as the best way to write management term paper is $36.60 \%(0.0448 / 0.1224)$.

Table 8: Educational Background

\begin{tabular}{|c|c|c|c|c|c|}
\hline & Arts and Science & Engineering & Business & Education & Total \\
\hline Individual & 0.1020 & 0.0448 & 0.2367 & 0.0040 & 0.3877 \\
\hline Team & 0.0775 & 0.0285 & 0.2653 & 0.0000 & 0.3714 \\
\hline Choices & 0.0285 & 0.0326 & 0.1183 & 0.0000 & 0.1795 \\
\hline Indifferent & 0.0081 & 0.0163 & 0.0367 & 0.0000 & 0.0612 \\
\hline Total & 0.2163 & 0.1224 & 0.6571 & 0.0040 & 1.0000 \\
\hline
\end{tabular}

\section{HYPOTHESIS TEST}

\section{Theoretical Framework}

A test of independence will be used to determine if the students' attitudes and preference toward the choices in term paper writing are significantly related to the selected variables. For example, are students' attitudes and preferences toward the choices in term paper writing strongly influenced by gender difference? Whether there is a difference between males and females with regard to their attitudes toward the method of writing term papers is a question answered with the aid of the $\chi^{2}$ test. The null and alternative hypotheses (Ho and Ha) are as follows:

Ho: the row variable (male or female in Table 2) is independent of column variable (students' attitude toward term paper writing approaches, i.e., individual, team, freedom of choice, and indifferent)

Ha: the row variable (male or female) is not independent of column variable (students' attitude toward term paper writing approaches, i.e., individual, team, freedom of choice, and indifferent) 
The test statistic for independence is the $\chi^{2}$ test, which is stated as

$\chi^{2}=\sum \sum\left(\mathrm{f}_{\mathrm{ij}}-\mathrm{e}_{\mathrm{ij}}\right)^{2} / \mathrm{e}_{\mathrm{ij}}$

where

$f_{i j}$ is observed frequency for contingency table category in row $i$ and column $j$

$e_{i j}$ is expected frequency for contingency table category in row $i$ and column $j$ based on the assumption of independence.

The null hypothesis will be rejected if the $\chi_{\text {calculated }}^{2} \chi^{2}$ table.

\section{Data and Model}

Data were collected using a survey distributed to students enrolled in the MBA and MSHCA degrees at a business school in a major metropolitan area in the Southeast. As a result of the survey, a sample of 257 observations was used to formulate and test the hypotheses in the study. Specifically, the impact of the following elements on students' attitudes and preferences toward the approaches of term paper writing in management courses were examined: age, gender, race/ethnicity, marital status, employment status, income level, work experience, and educational background.

\section{Empirical Results}

The test of independence was performed on each of the elements listed above. The $\chi^{2}$ statistic was used to test the significance of independence. At the $95 \%$ level of confidence, the test results reveal that students' attitudes toward the different approaches used in term paper writing are more significantly related to some of the demographic and socioeconomic factors such as gender, experience, and income. Meanwhile, the attitudes toward different approaches in term paper writing are independent of other factors, namely, age, marital status, employment status, race/ethnicity, and educational background. Table 9 shows the summary of the test results.

Table 9: Summary Of The Test Results Of Independence

\begin{tabular}{|c|c|c|c|c|}
\hline ELEMENTS & $\boldsymbol{\chi}^{\mathbf{2}}$ calculated & $\boldsymbol{\chi}^{\mathbf{2}}$ table & Decision On Ho & Impact On Attitude \\
\hline Age & 5.3496 & 16.9190 & Fail to reject & Insignificant \\
\hline Gender & 8.8159 & 7.8147 & Reject & Significant \\
\hline Race & 12.3649 & 16.9190 & Fail to reject & Insignificant \\
\hline Marital Status & 5.8494 & 7.8147 & Fail to reject & Insignificant \\
\hline Employment & 8.2650 & 12.5916 & Fail to reject & Insignificant \\
\hline Experience & 27.6489 & 12.5916 & Reject & Significant \\
\hline Income & 16.0773 & 12.5916 & Reject & Significant \\
\hline Education & 8.2194 & 16.9190 & Fail to reject & Insignificant \\
\hline
\end{tabular}




\section{CONCLUSIONS}

The implications of the empirical findings of the study may be bifurcated into two interrelated aspects: pedagogical approaches and diversity management. Overall, the former indicates that about $37.14 \%$ of students prefer the team approach to writing term papers in management courses while $38.77 \%$ prefer the individual approach. Approximately $17.00 \%$ of the students would prefer to have the freedom of choice. The remaining seven percent of the students are indifferent as to which approach to use.

The latter aspect, i.e., the implication to diversity management, is an important issue in pursuing institutional effectiveness of higher education and in achieving optimality of pedagogical approaches. This study examined one of the aspects of this issue: how to approaches term paper writing in a diverse academic environment. From the diversity management perspective, the empirical results indicate that the team approach is positively related to the following diversity factors: younger student, male students, African-American students, students with incomes from $35 \mathrm{k}$ to $75 \mathrm{k}$, single students, students with five years' work experience or less, full-time working students, and students with an undergraduate engineering background. The analyses of these diversity factors also suggest that students' attitudes toward the approaches used in writing management term papers are affected by age, gender, race/ethnicity, employment status, income, career levels, and educational background. Specifically, According to the results of the tests of independence, the impact of gender, work experience and income are more significant than the other factors selected in the study.

It will be the challenge of future studies to examine more thoroughly the mix and strength of diversity factors significantly affecting the attitudes of students toward specific methods of paper writing. Additional data on this subject would assist professors in identifying and executing a more targeted and efficacious pedagogy for achieving course objectives. In writing term papers, whether to use a team approach or an individual approach may also be a cultural issue. As aptly stated by Harrington-Mackin (1994): “Americans don't grow up learning how to function in teams. In school we never receive a team report and/or learn the names of the team of sailors who traveled with Columbus to America" (p. 43). Teams blend in better with cultures that score high on collectivism than those high on individualism, such as the ones in U.S., Canada, U.K. and Australia. It is important for us to know if this is also true in terms of term paper writing. Therefore, as a part of a series of studies, the next logical step will be to survey students in different cultures, in different countries and use the data collected to conduct international comparative studies of cultural impact on pedagogical approaches.

\section{REFERENCES}

1. Applebaum, E., and R. Blatt, the New American Workplace, Ithaca, New York, New York: ILR, 1994.

2. Banner, David K., Kulisch, W. Anthony, and Newman S. Peery (1992). Self-managing Work Teams (SMWT) and the Human Resource Function, Management Decision, Vol. 30, Iss. 3, London.

3. Bingham, Frank G. and Charles J. Quigley (Fall 1989). A Team Approach to New product Development, the Journal of Consumer Marketing, Vol. 6, Issue 4.

4. Bolton, M. K. (1999). The Role of Coaching Students Teams: A `Just-in-time` approach to Learning, Journal of Management Education, Vol. 23, Issue 3.

5. Bowen, Donald, D. (Feb. 1998). Team Frames: the Multiple Realities of the Team, Journal of Management Education, Vol. 22, Issue 1.

6. Chatman, Jennifer A. and Francis J. Flynn (October 2001). The Influence of Demographic Heterogeneity on the Emergence and consequences of Cooperative Norms in Work Teams, Academy of Management Journal, Vol. 44, Issue 5.

7. Darling, John R (July 1990). Team Building in the Small Business Firm, Journal of Small Business Management, Vol. 28, Issue 3.

8. Ettington, Debarah R., and Richard R. Camp (August 2002). Facilitating Transfer of Skills between Group Projects and work Teams, Journal of Management Education, Vol. 26, Issue 4.

9. Harrington-Mackin, D. (1994). The Team Building Tool Kit, New York, AMACOM, p. 43.

10. Katzenbach, J.R., and D. K. Smith (1993). the Wisdom of Teams, Harvard Business Press, Boston.

11. Robbins, Stephen P. (2000). Essentials of Organizational Behavior, Sixth Edition, Prentice Hall, p105. 
12. Tonn, Joan C., and Vicki Milledge (August 2002)., Team Building in an MBA 'Gateway' Course: Lessons Learned, Journal of Management Education, Vol. 26, Issue 4.

\section{NOTES}

